\title{
A Discussion to Presenting Texture Effects in Costume Designing in View of 3D Printing Technology
}

\author{
Junyung WANG \\ College of Textiles\&Garments, Southwest University, ChongQing, China \\ DOI: $10.15221 / 15.034 \quad$ http://dx.doi.org/10.15221/15.034
}

\begin{abstract}
:
The popularization and application of 3D printing technology, promote greatly the development of the apparel industry. But there are still some queries with the technology in the garment industry at the same time. Because of it's reproducible characteristics and can mass producing, most of people in this industry believe that the technology is lack of artistry. The printer can not replace the traditional handmade artistic creations and embroideries. However, like oil painting or computer graphics, the 3D printing technology is the carrier of art, it's artistry is no less than the handmade manufacture. This is a reflection ahead of it's time. Through the technical innovation, 3D printing technology can produce it's individuality, and also can solve the problems from the texture effects in costume and the limitations of color. The popularization of 3D digital printing already can implement the presence from different texture effects. Like the expressions of splash-ink, dizzy catch in ink and wash painting in Chinese wind of fashion design, the texture changes according to the profile. It often says in garment industry, "there is no texture you not produce, but the price." 3D printing technology will become the mainstream in costume designing by forming the clothing shape from the change of textures.

In this paper, we chose the case analysis as the main researching method. Using the special case of Iris van Herpen, a costume designer from Netherlands, and the modern art creation theory, we compared the art language directions between the 3D printing and the traditional handmade techniques. We discussed the improvement of performance in 3D printing technology. We introduced mostly about the technology used for presenting texture effects in Chinese wind of fashion design and discovering the diversity of color. Today 3D printing redefined "arts and crafts". By the development and innovation of the technology, it would be a more practical means of artistic creation.
\end{abstract}

Key words: 3D printing technology; costume; texture effects; traditional handmade

\section{Iris van Herpen and Her 3D Printing Works}

Iris van Herpen, the most popular and hottest geek costume designer in recent years, brought her 3D printing technology to the fashion week. Her talent and avant-garde let her become one of the brightest designers in the fashion week, and be considered as the representative of "conceptual costume". Once she practiced in the studios of Alexander McQueen, Claudy Jongstra and Viktor, those brands deeply influenced her design style. Her personal brand could be called the most successful designer brand in the 3D printing costume area. In 2011, by using 3D printing technology, she designed a 3D stereoscopic garment. She was highly regarded in the high-ranking custom fashion area by her bold and strange conception, and her clever ideas from the natural world.

Iris van Herpen was not satisfied with the expressive ability from the traditional soft fabric, she needed a new material which could help her to attempt to breakthrough for the structure and the modelling of the garment. In her process, she needed to symbolize the natural images firstly, then break up those symbols, after that, recombine them, let them become three dimensional, at last, structuralize them with the curve of human body. Like this kind of design, the traditional way was hard to achieve. But if you used the new 3D printing technology, you could easily solve the problems in fabrication. Like this, Iris van Herpen started to research in this area, she created some amazing works with her 3D printing technology. At the same time, she collaborated with a Belgian company, named Materialise NV. She gave them her designing works, they made the fabrications for her. Right now Iris van Herpen was frequently appeared in all the big fashion shows, and her designing works were collected by a lot of museums. In 2011, her works were listed in the annual top 50 inventions in Times. And the "Ice queen" Anna Wintour gazed her fashion shows without her dark glasses. In contrast with the traditional fashion, Iris van Herpen was good at expressing the garments in different art forms. Her bold experiment for the materials, process and techniques of garments was a revolutionary innovation. Her futuristic garment technique became her emblematic feature. 


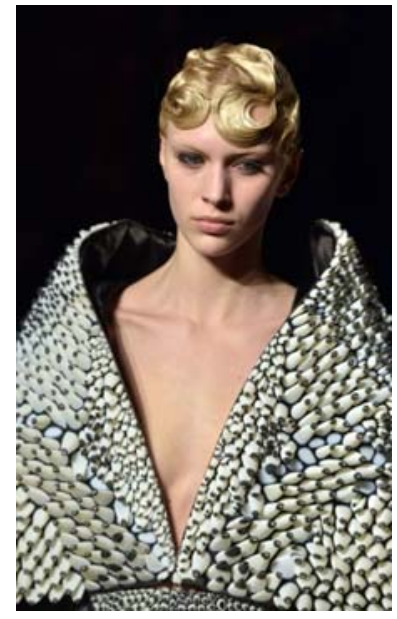

To some extent, the designing works of Iris van Herpen was a crossover, a mixture of garments, architecture and product. The ideas of her design were similar to the designing works of the lamps and lanterns of Italy. In fact, it was easy and harmonious to add some lighting elements in her design. Maybe we could see this in her fashion show pretty soon. The picture above was one of her designing works from the spring and summer haute couture fashion show in Paris. Iris van Herpen had 11 works in this show which named Voltage. The picture below was an amplification performance of details of this garment by using 3D printing technology. It produced by Stratasy-Objet Connex 3D printer. Iris van Herpen was especially good at designing from the material of clothes, and add some exaggerated modellings. In fashion circle, people often called her Alexander McQueen the second, and also called her the real "cubist".

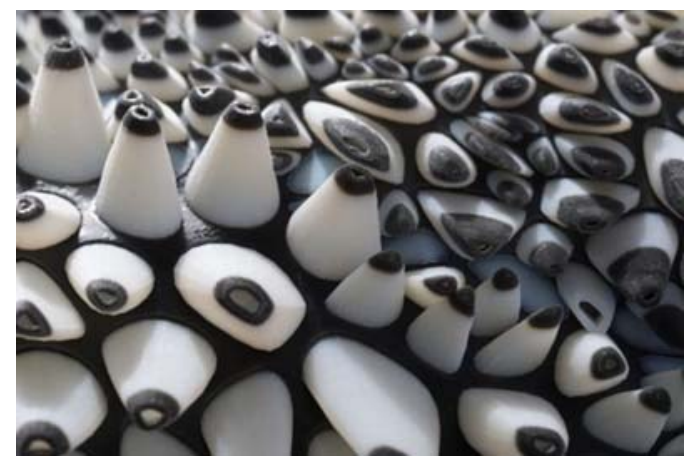

\section{To Transform the Wearability of Garments and Present Texture Effects in View of 3D Printing Technology}

Material was the key to restricting the $3 \mathrm{D}$ printing effect. Poor material formability and lack of precision much influenced the appearance and the service life of the finished product. Under normal circumstances, polyester fiber and natural fiber were frequently used in the production of clothing fabric. After the knitted or woven process, the fabrics were made by sewing. But the traditional way was not suitable for the 3D printing technology. Therefore, we needed to find out a new chemical fiber material, which not only could achieve the requirement of the forming fabrics and dissolving the consumable materials, but also could allocate the color and achieve the requirement of textiles, and suitable for the human body. The 3D printers on the market now used the powdered raw material. But the textile materials, using for the production, could not completely deal with it. That restricted deeply the application of 3D printing technology in the clothing design. Moreover, the color of 3D printing material restricted the application of the technology either. Of course, with the continuous improvement of textile materials, and the new born 3D printers, it would provide a broader selection of materials. 
The productions of clothing by 3D printing technology were rapid prototypical. To comparable with the productions fabricated by the traditional way, they had less close-skin resistance, softness and comfort. Because they were the productions of multilayer superposition, and they needed to form the raw material by different ways, they were not only lack of flexibility and stretchability, but also had large constriction to the human body, which affected people's normal activity.

Although the comfortability and wearability of $3 \mathrm{D}$ printing textures had long been criticized, Iris van Herpen started to have a real attempt to let her models wearing the 3D printing garments during her published autumn and winter series in 2015 . The brightest point of the series was still the shell fabric. The special texture of $3 \mathrm{D}$ printing, the dreamful tonal and halo as the marine life, and the coexistence profile of lightness and immanent power, provided an experience which could not have in traditional way. It's worth noting that, unlike the previous parts, some of the too exaggerated and dramatic modellings were abandoned in this series. The whole modelling changed to stream line form. Though it had not the full-tension and artistic feeling, the series showed the unique creative idea and powerful aura of the brand. That satisfied the impact of the visual, and closed more to the everyday life. To combine the Chinese dress and the skeleton-like texture fabrics, was a very surprising attempt. The soft Chinese dress stood up the first time by the new texture fabrics of third dimension.
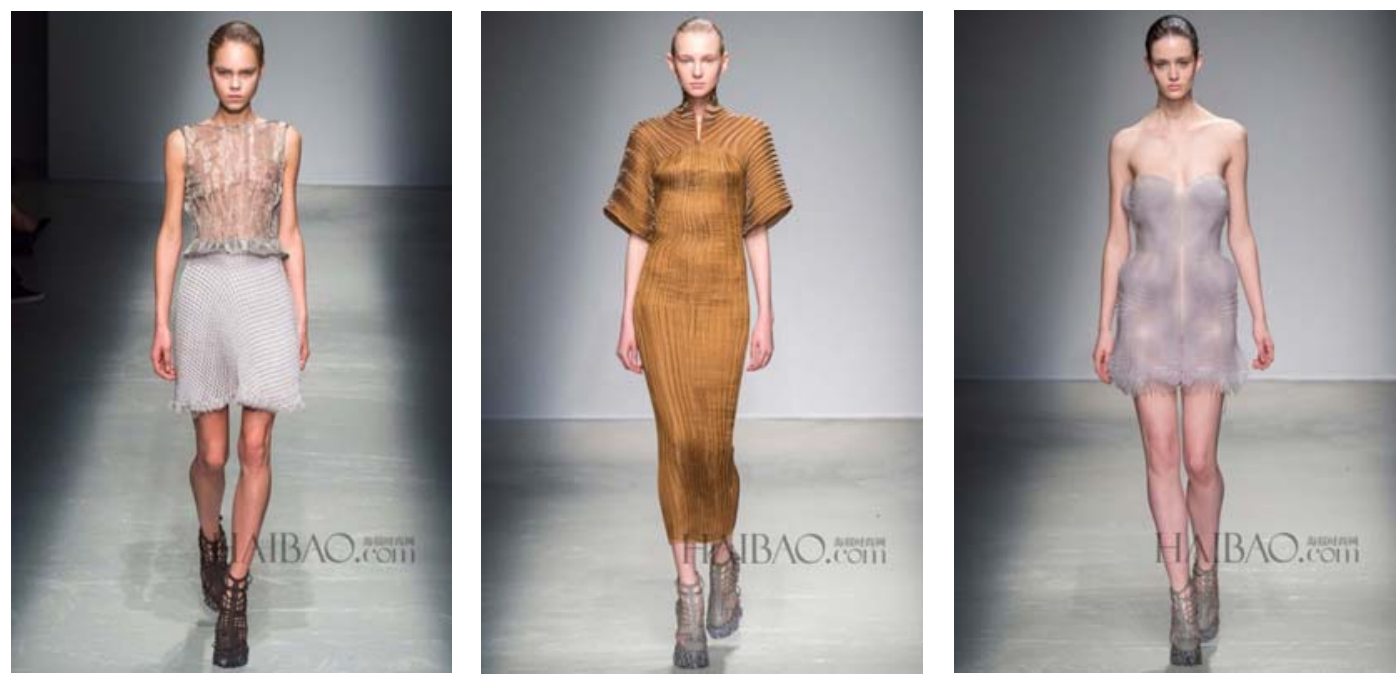

The application of 3D printing technology in apparel industry, created the stereoscopic modelling, which the cloth could not express. And it gave people a brand new impact of visual. The 3D printing garments were different from the productions fabricated by traditional way in style, pattern and fabrics. You could print all the styles you could imagine by 3D printing technology. Right now, it already succeeded to produce the dresses, underwears, shoes and decorations. Patterns of a garment was the vitality of clothes endowed by the designer. Therefore, pattern design was the key to the success. The traditional hand-made productions did not have the delicate and beautiful effect like 3D printing works. Using 3D printing technology could link up the dot, line, face and body in multidimensional space. For promoting the wearability of 3D printing garments, we had two ways to go: firstly, we needed improve the equipment by the development of techniques; secondly, we should create a mode by 3D printing technology and hand-made fabrication, which was the best way to find out nowadays.

When the clothes produced by this mode, you could use 3D printing technology widely in many parts of stereoscopic modelling, which needed pay attention on. That got much faster and had a very prominent stereoscopic effect. You could use hand-made fabrication in some parts, which needed a large activity. This could set aside the appropriate relax, and increase the comfort against the body. This mode increased not only the speed, but also promoted the wearability.

Presenting texture effects in 3D printing technology was an other problem which needed urgently to solve. The fabric could be created again through the way of recreation on the 3D printing clothes. Taking advantages of the pure art, you could fabricate the texture on the clothes by the pigments or dyes that attached to the 3D materials. It could be ink effects, and it could be also cracked effects. By the development of techniques, maybe you could change the 3D digital printing or other printing way, and directly print all the different effects on the 3D fabrics pretty soon. 


\section{The conclusion}

Though it had less wearability, the 3D printing technology developed fast today. The apparel industry had generally started to discover the renovation of wearability to the 3D printing clothes. Iris van Herpen, the pioneer designer of 3D printing area, started to have a real attempt to let her models wearing the 3D printing garments during her published autumn and winter series in 2015. I believed that more and more designers would go into the ranks of the experiment. The future developed equipment and new fabric would improve the comfortability and wearability of clothes surely, but right now creating a mode by 3D printing technology and hand-made fabrication was the only way to go. For presenting texture effects, we should improve our printing ways and try new ones. We should also fabricate the texture on the clothes in pure art method, and create the fabric again through the way of recreation. I believed that the bottleneck of 3D printing technology would be breached soon, and this technology would develop faster and better.

\section{Bibliography}

[1] 中文业界资讯站.艾瑞斯·凡·赫本（Iris van Herpen）的 3D 打印时装设计之路［EＢ／ＯL］ http://www.cnbeta.com/articles/224028.htm 2013-01-27

[2] 巫朝港.3D 打印技术在现代服装中的运用[J]. 艺术科技,2015,01:11+127+168.

[3] 王修春,魏军,伊希斌,张晶,尚开,王黔. 3D 打印技术类型与打印材料适应性[J]. 信息技术与信息 化,2014,04:84-86+90. 